\title{
THE EFFECT OF POSTURE ON THE ROLE OF THE APOPHYSIAL JOINTS IN RESISTING INTERVERTEBRAL COMPRESSIVE FORCES
}

\author{
M. A. ADAMS, w. C. HUTTON \\ From the Polytechnic of Central London
}

\begin{abstract}
Cadaveric lumbar intervertebral joints were loaded to simulate the erect standing posture (lordosis), and the erect sitting posture (slightly flexed). The results show that, after the intervertebral disc has been reduced in height by a period of sustained loading, the apophysial joints resist about 16 per cent of the intervertebral compressive forces in the erect standing posture, whereas in the erect sitting posture they resist none. The implications of this in relationship to degenerative changes and to low backache are discussed.
\end{abstract}

For the purpose of this article the term "intervertebral joint" is taken to include not only the apophysial joints, but also the two adjacent vertebrae and the intervening disc. The plane of the articular facets is approximately at right angles to the plane midway through the intervertebral disc. This, together with the absence of any articular cartilage at the tips of the facets, suggests that the primary role of the apophysial joints is to transmit shear forces across the intervertebral joint.

However, the close proximity of the tips of the articular facets to the adjacent laminae suggests that contact may frequently take place. Although such contact would relieve the intervertebral disc of compressive force, it might, in itself, be a cause of low backache, possibly by compressing the joint capsule. Certainly the apophysial joints sometimes become osteoarthritic, with denudation of articular cartilage and with osteophyte formation.

The purpose of our work was to determine what proportion of intervertebral compressive force is borne by these apophysial joints. Although others had touched upon this subject (Nachemson 1963; Markolf 1972) we felt further study was needed and we here present our experiments; these take account of the posture (that is, the angle of flexion or extension), the amount of intervertebral disc creep under constant load, the variation between the different levels of the spine, and the degree of intervertebral disc degeneration.

\section{MATERIAL AND METHODS}

The lumbar spines of 18 cadavers in which there was no evidence of bone disease were removed. These spines were stored in sealed polythene bags at -20 degrees Celsius. Before being tested, they were thawed in their bags, then taken out and cut into specimens, each consisting of two vertebrae and the intervening joint. Care was taken to excise any soft tissue which might prevent efficient fixation in plaster. Each vertebra was then embedded in a mildly exothermic * Sold by Cottrell and Co., Charlotte Street, London W1.

fast-setting dental plaster sold under the trade name of Stonehard*. Wood screws were inserted into the vertebral bodies to ensure that the plaster had a firm hold. Each specimen was so positioned that the plane midway through the intervertebral disc was parallel to the ends of the cups which contained the plaster. Care was taken that the neural

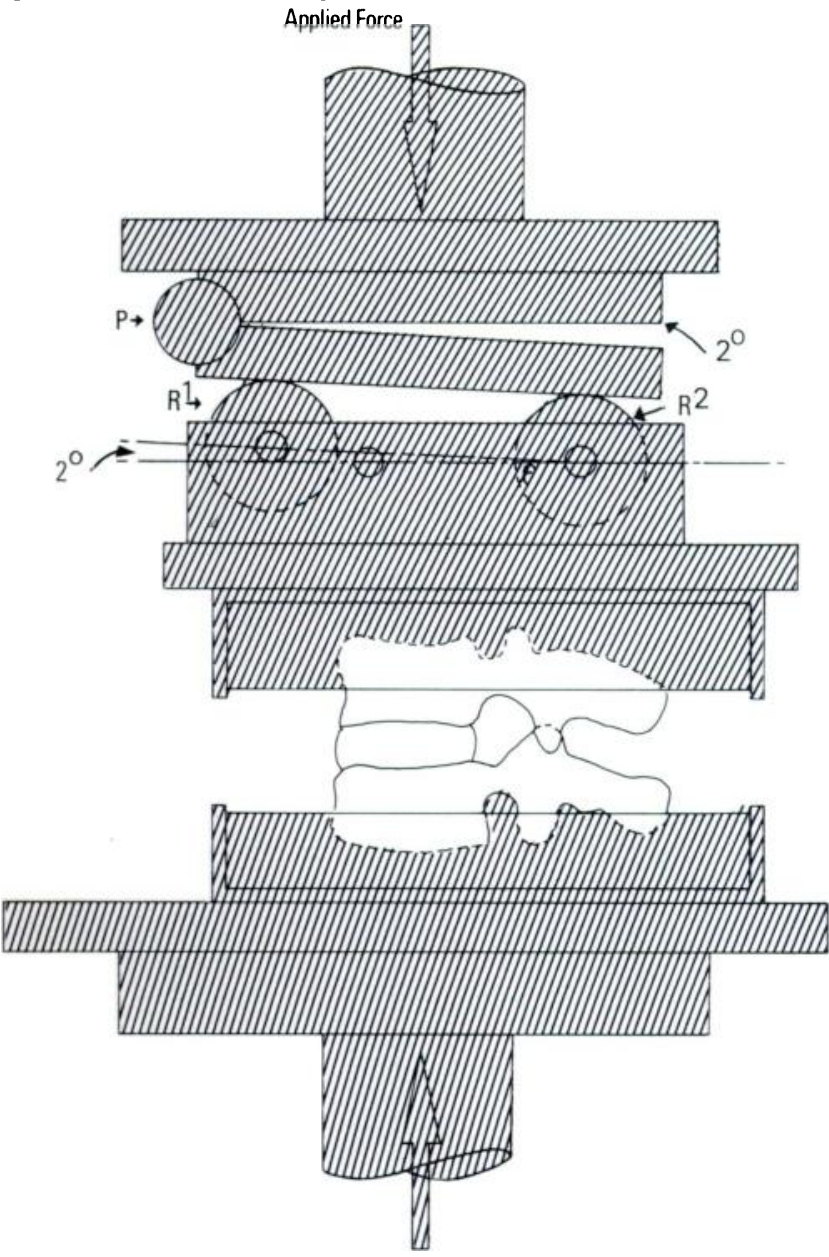

Fig. 1

The apparatus for loading an intervertebral joint in compression. $\mathrm{P}$ is the angle plate, $R^{1}$ and $R^{2}$ the rollers (see text).

M. A. Adams, BSc, Research Assistant

Polytechnic of Central London,

W. C. Hutton, MSc, CEng, MIMechE, Principal Lecturer $\int 115$ New Cavendish Street, London W1M 8JS, England.

Requests for reprints should be sent to Mr W. C. Hutton. 
arches were firmly embedded in the plaster in order to keep the articular facets of the apophysial joints in close apposition as occurs in life.

Each specimen was then subjected to a series of compressive tests. The entire process of dissection, fixation and testing was completed within five hours; during this time the joint was kept moist with cotton wool soaked in normal saline. After testing, each disc was examined macroscopically for degeneration and was scored on a scale from one to four as described by Galante (1967).

The apparatus is shown in Figure 1. The angle plate $(\mathrm{P})$ may be set closed (horizontal), or opened to a maximum of two degrees. The rollers $\left(R^{1}, R^{2}\right)$ also may both be on the same level (horizontal), or at an angle of two degrees. With both plate and roller horizontal any compressive force would be applied to the intervertebral joint in the neutral position (referred to as " 00 "). . Opening the angle of the plate by two degrees is equivalent to two degrees of extension at the intervertebral joint; opening the angle between the rollers contributes a further two degrees of extension. These amounts are referred to as $"-2^{\circ "}$ and " -4 " respectively. In addition the entire apparatus with its contained vertebrae can be swivelled through 180 degrees between the plate and the rollers; angles of two degrees and four degrees of flexion (" $+2^{\circ \cdot "}$ and $\left."+4^{\circ \prime \prime}\right)$ can then be obtained.

It is true that loading the joint in this way imposes not only a compressive force, but also a shear force. At an angle of two degrees, a compressive force of 1000 newtons imposes a shear force of 35 newtons. Cyron (1977) has shown that a force of this magnitude may safely be neglected. The apparatus measures only vertical forces, and is servo-controlled. It applies a load increasing at the rate of 300 newtons per second up to a predetermined maximum and then back to zero, while an $X-Y$ recorder plots the force against the vertical displacement. The maximal force applied to each joint was proportional to the body weight of that individual, based on a standard force of 1000 newtons for an individual weighing 70 kilograms; this is approximately the compressive load on lumbar discs in the erect standing position (Nachemson 1966).

Specimens, each consisting of two adjacent vertebrae with the intervening disc, were taken and randomly divided into two groups. Each specimen in Group 1 was first loaded at $0^{\circ}$ and a deformation curve obtained. After an interval of five minutes (which previous tests had established to be sufficient to give reproducible results), the specimen was loaded at $+2^{\circ}$ and a further curve obtained. Similar curves were obtained at $-2^{\circ}$ and, if the specimen was sufficiently flexible, at $+4^{\circ}$ and at $-4^{\circ}$. These deformation curves are labelled $\mathrm{A}$ in Figure 2. The neural arch was then cut through with a hacksaw. It was cut in two lines parallel to the midline of the disc, and a section three millimetres thick was removed. The entire series of loading experiments was then repeated, and the deformation curves obtained are labelled $B$ in Figure 2.

The specimens in Group 2 were treated differently. Each was first subjected to a constant compressive load (equal in amount to the maximum previously mentioned) for three hours. After two hours the disc had lost about 10 per cent of its height, but in the third hour it lost only a further one per cent. Before proceeding with the loaddeformation experiments it was necessary to allow an interval of 10 minutes to elapse; otherwise the swelling of the disc as it recovered gave unreliable readings. After 10 minutes the disc had regained about two per cent of its height and the rate of swelling had decreased to a low and fairly constant level.

The load-deformation curves were then obtained as follows. Because the recovering disc was continuing to swell, repetition at any given angle did not give identical curves; successive curves were displaced a small regular distance along the $X$ axis. This displacement was quantified by testing at $+2^{\circ}$ and $-2^{\circ}$ in rapid succession, then repeating both after five minutes and again after a further five minutes. A correction factor was obtained and this was applied in obtaining the curve after the facets had been cut, a procedure which took five minutes. Curve $A$ in Figure 2 is the final curve before the facets were cut and Curve $B$ the first after cutting. Because of a number of technical difficulties the specimens in Group 2 were tested only at $+2^{\circ}$ and $-2^{\circ}$.

The possibility of "kissing" spinous processes was tested by passing a scalpel blade through the supraspinous and interspinous ligaments while the joint was loaded at $-2^{\circ}$ (or at $-4^{\circ}$ if tested at this angle); this was done just before the facets were cut. In two specimens (numbers 29 and 30) the spinous processes were found to be touching, so an intermediate.curve was obtained with the lower part of the upper spinous process removed but with the facets still intact. From this intermediate curve the percentage load resisted by the spinous processes was calculated. In all the other joints tested no compressive load was transmitted by the spinous processes.

A rapid loading rate ensured that the total error in the $X$ axis, due mostly to the variability of disc recovery, was less than 0.01 millimetre; this implies an uncertainty of about 30 newtons in the load values, with a maximal error of \pm 3 per cent in assessing the load on the apophysial joints. To measure this load, Curve $B$ is subtracted from Curve $A$ to give Curve $C$, the resistance curve for the facets*. The load on the facets at the physiological compressive load is $h c$.

\section{RESULTS}

Typical curves expressing the amount of vertical compression resulting from varying compressive loads are shown in Figure 2. Only those in two degrees of flexion $\left(+2^{\circ}\right)$ and two degrees of extension $\left(-2^{\circ}\right)$ are given. The curves for four degrees of flexion and extension were similar, while those in neutral position $\left(0^{\circ}\right)$ were between those at $+2^{\circ}$ and $-2^{\circ}$. The dotted lines at the lower end of each curve represent the initial

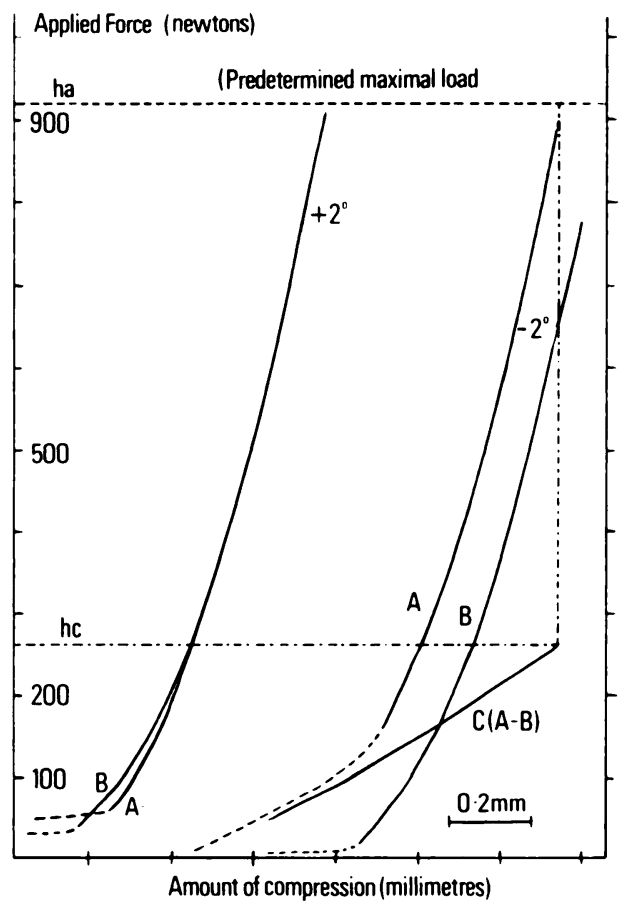

Fig. 2

Typical curves showing the amount of deformation when compressive loads are applied in two degrees of flexion $\left(+2^{\circ}\right)$ and two degrees of extension $\left(-2^{\circ}\right)$. Curves $A$ are before the neural arches were cut, and Curves $B$ after. Curve $C$, obtained by subtracting B from A, represents the deformation curve for the apophysial joints, while $h c$ (obtained by dropping a vertical line from the intersection of $A$ with $h a$ ) is the load carried by these joints at $-2^{\circ}$.

*It should be pointed out that it is incorrect to compare gradients of Curves $A$ and $B$. The gradient is a measure of the rate of change of load-bearing with distance compressed and is proportional to total load resisted only if the graphs are straight lines. 
M. A. ADAMS, w. c. HUTTON

Table I. Detailed results in 40 intervertebral joints from the 18 cadaveric spines. The specimens in Group 2 were subjected to constant loading for three hours before testing

\begin{tabular}{|c|c|c|c|c|c|c|c|c|c|c|c|c|}
\hline \multicolumn{8}{|c|}{ Specimen detalls } & \multicolumn{5}{|c|}{ Percentage load on facets } \\
\hline $\begin{array}{l}\text { Specimen } \\
\text { number }\end{array}$ & Sex & $\begin{array}{c}\text { Age } \\
\text { (years) }\end{array}$ & Level & $\begin{array}{l}\text { Severity of dibc } \\
\text { degeneration * }\end{array}$ & $\begin{array}{l}\text { Body mass } \\
\text { (kilograms) }\end{array}$ & $\begin{array}{c}\text { Applied load } \\
\text { (newtons) }\end{array}$ & $\begin{array}{c}\text { Height lost } \\
\text { (millimetres) }\end{array}$ & $-4^{8}$ & $-2^{\circ}$ & $-0^{\circ}$ & $+2^{\circ}$ & $+4^{\circ}$ \\
\hline Group 1 & & & & & & & & & & & & \\
\hline 1 & $\mathbf{M}$ & 25 & L5-S1 & 1 & 49 & 700 & - & 56 & 36 & 13 & 6 & \\
\hline 2 & $\mathbf{F}$ & 33 & L3-4 & 1 & 41 & 590 & - & & 6 & 0 & 0 & \\
\hline 3 & $\mathbf{F}$ & 44 & L1-2 & 2 & 32 & 460 & - & 9 & 0 & 0 & 0 & 0 \\
\hline 4 & $\mathbf{F}$ & 44 & L5-S1 & 2 & 32 & 460 & - & 11 & 0 & 0 & 0 & 0 \\
\hline 5 & $\mathbf{M}$ & 47 & L2-3 & 2 & 46 & 660 & - & & 6 & 0 & 0 & \\
\hline 6 & $\mathbf{M}$ & 47 & L4-5 & 2 & 46 & 660 & - & & 0 & 0 & 0 & \\
\hline 7 & $\mathbf{M}$ & 58 & L1-2 & 2 & 70 & 1000 & - & 4 & 0 & 0 & 0 & 0 \\
\hline 8 & $\mathbf{F}$ & 65 & LS-S1 & 4 & 45 & 640 & - & & 37 & 5 & 5 & \\
\hline 9 & $\mathbf{F}$ & 69 & L3-4 & 4 & 57 & 810 & - & & 11 & 0 & 0 & \\
\hline 10 & $\mathbf{M}$ & 79 & $L 1-2$ & 3 & 45 & 640 & - & & 7 & 0 & 0 & \\
\hline 11 & $\mathbf{M}$ & 79 & L5-S1 & 3 & 45 & 640 & - & & 2 & 0 & 0 & \\
\hline 12 & $\mathbf{M}$ & 80 & $L 1-2$ & 4 & 60 & 860 & - & & 12 & 7 & 5 & \\
\hline 13 & $\mathbf{M}$ & 80 & L3-4 & 4 & 60 & 860 & - & & 0 & 0 & 0 & \\
\hline Group 2 & & & & & & & & & & & & \\
\hline 14 & $\mathbf{M}$ & 25 & L3-4 & 1 & 49 & 700 & 1.2 & & 38 & & 0 & \\
\hline 15 & $F$ & 33 & L1-? & 1 & 41 & 600 & 0.7 & & 4 & & 0 & \\
\hline 16 & $\mathbf{F}$ & 33 & L5-S1 & 1 & 41 & 650 & 1.0 & & 12 & & 8 & \\
\hline 17 & F & 37 & L2-3 & 2 & 72 & 1030 & 1.1 & & 22 & & 0 & \\
\hline 18 & $\mathbf{F}$ & 37 & L4-5 & 2 & 72 & 1030 & 1.2 & & 9 & & 0 & \\
\hline 19 & $\mathbf{M}$ & 41 & L2-3 & 1 & 63 & 900 & 1.0 & & 11 & & 0 & \\
\hline 20 & $\mathbf{M}$ & 41 & L4-5 & 1 & 63 & 900 & 0.9 & & 16 & & 0 & \\
\hline 21 & $\mathbf{F}$ & 44 & L2-3 & 2 & 52 & 750 & 0.9 & & 7 & & 0 & \\
\hline 22 & $\mathbf{F}$ & 44 & L4-5 & 2 & 52 & 750 & 1.0 & & 9 & & 0 & \\
\hline 23 & $\mathbf{M}$ & 55 & L2-3 & 3 & 63 & 900 & 0.7 & & 7 & & 0 & \\
\hline 24 & $\mathbf{M}$ & 55 & L4-5 & 3 & 63 & 900 & 0.8 & & 17 & & 0 & \\
\hline 25 & $\mathbf{M}$ & 58 & L5-S1 & 2 & 71 & 1000 & 1.0 & & 64 & & 9 & \\
\hline 26 & $\mathbf{M}$ & 51 & L4-5 & 3 & 73 & 1030 & 1.2 & & 13 & & 0 & \\
\hline 27 & $\mathbf{M}$ & 64 & L3-4 & 4 & 70 & 1000 & 1.1 & & 16 & & 0 & \\
\hline 28 & $\mathbf{M}$ & 64 & L5-S1 & 4 & 70 & 1000 & 1.1 & & 34 & & 9 & \\
\hline 29 & $\mathbf{F}$ & 64 & $\mathrm{Ll}-2$ & 4 & 45 & 640 & 1.0 & & 70 & & 0 & \\
\hline 30 & $\mathbf{F}$ & 65 & L3-4 & 4 & 45 & 640 & 1.4 & & 70 & & 14 & \\
\hline 31 & $\mathbf{M}$ & 65 & $\mathrm{Ll}-2$ & 3 & 96 & 1300 & 0.8 & & 0 & & 0 & \\
\hline 32 & $\mathbf{M}$ & 65 & L5-S1 & 3 & 96 & 1300 & 1.7 & & 0 & & 0 & \\
\hline 33 & $\mathbf{F}$ & 69 & $\mathrm{Ll}-2$ & 3 & 57 & 810 & 1.2 & & 11 & & 5 & \\
\hline 34 & $F$ & 69 & L5-S1 & 3 & 57 & 810 & 0.8 & & 18 & & 0 & \\
\hline 35 & $F$ & 71 & L1-2 & 3 & 39 & 560 & 1.1 & & 8 & & 0 & \\
\hline 36 & $\mathbf{F}$ & 71 & L3-4 & 3 & 39 & 560 & 1.2 & & 10 & & 0 & \\
\hline 37 & $F$ & 71 & L5-S1 & 3 & 39 & 560 & 1.0 & & 20 & & 0 & \\
\hline 38 & $\mathbf{M}$ & 78 & L2-3 & 3 & 63 & 900 & 1.2 & & 27 & & 0 & \\
\hline 39 & $\mathbf{M}$ & 78 & L5-S1 & 3 & 63 & 900 & 1.2 & & 4 & & 0 & \\
\hline 40 & $\mathbf{M}$ & 79 & L3-4 & 3 & 45 & 750 & 1.0 & & 19 & & 0 & \\
\hline
\end{tabular}

- Scored on the scale of Galante (1967) 
bending of the joint when only one roller was in contact with the angle plate. The curves can be interpreted as follows.

Compression in two degrees of flexion. Curve $A$ (before cutting the neural arches) and Curve B (after cutting them) converge and at high loads coincide. At low loads, Curve $B$ is displaced to the left indicating that, with the neural arch cut, greater loads must be applied to obtain the same amount of compression of the disc. This difference can be attributed to prestressing of the disc by the ligamentum flavum in flexion. When the neural arch has been cut the ligament is of necessity also divided, and extra compressive force must be applied to obtain the same amount of compression of the disc as before.

Compression in two degrees of extension. Curves $A$ and $B$ do not converge, and Curve $C$ (representing the difference between them, and therefore the load on the apophysial joints) is approximately linear. In extension the ligamentum flavum exerts no prestressing influence. Compression in the neutral position. The curves obtained were intermediate to those in flexion and extension, with any features less marked.

The percentage of the compressive load which is borne by the apophysial joints at physiological loads is given by $h c / h a$. The results for each joint are given in Table I.

Four joints showed gross pathological changes: there was marked narrowing of the discs in Specimens 8 , 29 and 30, and extreme facet asymmetry in Specimen 1 from a patient with scoliosis. In all four a very large proportion of the compressive load was transmitted through the apophysial joints. Specimens 29 and 30 also had "kissing spines" in two degrees of extension; the proportion of the compressive load transmitted through

Table II. The amount of compressive force transmitted through the apophysial joints. The figures are percentages and are averages of all the normal joints *

\begin{tabular}{|c|c|c|c|c|c|}
\hline & $-4^{\circ}$ & $-2^{\circ}$ & $0^{\circ}$ & $+2^{\circ}$ & $+4^{\circ}$ \\
\hline Group 1 & 8 & 4 & 1 & 0 & 0 \\
Group 2 & & 16 & & 1 & \\
\hline
\end{tabular}

* Specimens 1.8.29 and 30 are omitted

Table III. Lumbar curve angles (measured from $L 1$ to $S 1$ ) for normal subjects in the erect standing and the erect sitting postures, obtained from radiographs

\begin{tabular}{|l|c|c|}
\hline \multicolumn{1}{|c|}{ Posture } & $\begin{array}{c}\text { Average lumbar } \\
\text { curve } \\
\text { (degrees) }\end{array}$ & $\begin{array}{c}\text { Number } \\
\text { in sample }\end{array}$ \\
\hline Erect standing & 52 & 20 \\
Erect sitting (arms on lap) & 29 & 10 \\
Excised cadaver joints * & 41 & 182 \\
\hline
\end{tabular}

*From Farfan. Huherdeau and Duhow (1972) the spinous processes in these two cases was 18 per cent and 14 per cent respectively. The average values presented in Table II do not include the results for these four specimens because they would distort the figures for normal spinal joints. These average values show that a significant compressive load is borne by the facets only when the disc has been narrowed by creep loading and the joint is in two degrees of extension.

From Table I, it is evident that the load borne by the apophysial joints is greater in the three lower joints than the upper lumbar joints. The average at the three lowest joints (L3-4, L4-5 and L5-S1) at two degrees of extension is 19 per cent of the total load; the average at the remaining lumbar joints (L1-2 and $L 2-3)$ is 11 per cent. This difference is statistically significant $(P<0.05)$.

There is no significant variation in load-bearing with age or with degeneration of the discs.

\section{DISCUSSION}

The results for Group 1 show that the intervertebral disc in all postures is required to bear most of the intervertebral compressive load. The joints in Group 2 had a constant compressive load applied to them for three hours to simulate the weight of the upper trunk plus the action of the postural muscles. These joints lost about nine per cent of their height: a similar loss could occur in vivo after prolonged standing or sitting. The apophysial joints then play a considerable part in resisting the intervertebral compressive force. Although the precise figure varies with each individual, the results show that on average about 16 per cent of the force is carried by the apophysial joints with the spine two degrees extended-that is, in the erect standing position.

Table III compares the values of the total lumbar curves obtained from the radiographs of excised cadaver spines and of normal subjects. The lumbar curve is here defined as the angle between the mid-planes of the L1-2 disc and the L5-S1 disc. In our experiments we altered the angle at each level by \pm 2 degrees and, since the lumbar curve includes four discs, the total change is \pm 8 degrees. Because the average curve in the lumbar spine is 41 degrees (see Table III), it is clear that the positions in our experiments correspond roughly to erect sitting $(41-8=33$ degrees $)$ and to erect standing $(41+8=49$ degrees).

However, when moving from the erect standing to the erect sitting posture, the angular changes are not equal at all levels (Andersson et al. 1979). The greatest changes occur at L3-4 and at L4-5 so that our values for the loads carried by the apophysial joints in the simulated erect standing posture are unduly low at these levels. Similarly, at $\mathrm{L} 1-2$ and at $\mathrm{L} 2-3$ they are unduly high.

Nachemson (1966) reports that the lumbar intradiscal pressure is higher in unsupported sitting than it is in erect standing; our results agree with this. In erect standing, the intervertebral compressive force may be 
shared between the discs and the apophysial joints, with the latter taking a high proportion of the load in some cases. In unsupported sitting (that is, in the slightly flexed posture) the apophysial joints take no part in resisting the intervertebral compressive force and the disc has the added burden of resisting the tension in the posterior ligaments. Previous work (Adams, Hutton and Stott 1980) has shown that the posterior ligaments can resist a considerable proportion of the bending moment exerted by the upper trunk when in flexion, and this results in high compressive loads on the intervertebral discs.

If, therefore, the aim is to reduce the compressive forces on the disc, then some degree of lordosis is needed. This posture, however, in addition to loading the apophysial joints, places high compressive loads on the posterior annulus, which is the focus of degenerative changes (Fahrni 1975). It has indeed been suggested that our Western lordotic posture promotes intervertebral disc degeneration (Fahrni 1975). Slight flexion on the other hand has the advantage of relieving both the apophysial joints and the posterior annulus of compressive force.

What are the implications of a high load being carried by the apophysial joints? The load might be transmitted across the fibrous capsule of the joint. This contains a nociceptive Type IV receptor system which is normally inactive but is stimulated by high mechanical stress (Nade, Bell and Wyke 1980). Sustained loading could thus produce pain. However, there is the further possibility that chronic overloading of the articular cartilage might encourage the development of osteoarthritis. The absence of articular surfaces perpendicular to the compressive force means that small forces will produce very high pressures at the point of contact. In our series several of the specimens which carried high loads on the apophysial joints were denuded of articular cartilage and had developed osteophytes. Such changes have been reported in the absence of disc degeneration or facet asymmetry (Lewin 1964), to which it cannot therefore be assumed they are secondary. We found that the apophysial joints at the three lowest lumbar levels carried higher loads than the upper two levels, and it is precisely these lower joints which are most often osteoarthritic (Lewin 1964).

The role of the apophysial joints in resisting intervertebral compressive forces might also be an important factor, though not the commonest one (Hutton and Cyron 1978), in the aetiology of spondylolysis; this might explain the high incidence in those athletes who frequently hyperextend their spines.

Specimens 8, 29 and 30 showed extreme narrowing of the disc and waisting of the vertebral bodies but no osteophytes in the vertebral body. Most of the compressive load in these specimens was carried by the apophysial joints, and these showed gross osteoarthritic changes. Specimen 29 showed distinct notches in the lamina of $\mathrm{L} 1$, apparently made by the superior facets of L2; all the facets of this specimen had an ivory-like rim with osteophytes. The spinous processes of Specimens 29 and 30 bore compressive forces at $-2^{\circ}$; this implies compaction of the interspinous ligament, which might be a potent source of pain. The results in these three specimens suggest that abnormal loading of the facets occurs whenever the height of the intervertebral disc is greatly reduced.

Specimen 1, with scoliosis and extreme asymmetry of the facets, was found to have a high load on the facets. Although this might have been due to the method of testing (in order to keep the disc plane horizontal, the facets were necessarily askew), the asymmetry is probably significant since a high incidence of degenerative changes has been reported in lumbar apophysial joints with asymmetrical facets (Badgley 1941). Asymmetrical facets may also lead to lumbar instability (Cyron and Hutton 1980). Thus, joints which transmit a high proportion of intervertebral compressive load through their apophysial joints, and which also have asymmetrical facets, must be at great risk of developing degenerative changes and causing low backache.

This project is supported by funds from the National Fund for Research into Crippling Diseases. Mr R. Emerson very kindly supplied technical assistance.

\section{REFERENCES}

Adams MA, Hutton WC, Stott JRR. The resistance to flexion of the lumbar intervertebral joint. Spine 1980; in press.

Andersson GBJ, Murphy RW, Örtengren R, Nachemson AL. The influence of backrest inclination and lumbar support on lumbar lordosis. Spine 1979;4:52-8.

Badgley CE. The articular facets in relation to low-back pain and sciatic radiation. J Bone Joint Surg 1941;23:481-96.

Cyron BM. Mechanical factors in the etiology of spondylolosis. PhD thesis. Polytechnic of Central London, 1977.

Cyron BM, Hutton WC. Articular tropism and stability of the lumbar spine. Spine 1980;5(2):168-172.

Fahrni WH. Conservative treatment of lumbar disc degeneration: our primary responsibility. Orthop Clin North Am 1975;6:93-103.

Farfan HF, Huberdeau RM, Dubow HI. Lumbar intervertebral disc degeneration. J Bone Joint Surg [Am] 1972;54-A:492-510.

Galante JO. Tensile properties of the human lumbar annulus fibrosus. Acta Orthop Scand [Suppl] 1967;100.

Hutton WC, Cyron BM. Spondylolysis-the role of the posterior elements in resisting the intervertebral compressive force. Acta Orthop Scand 1978;49:604-9.

Lewin T. Osteoarthritis in lumbar synovial joints. Acta Orthop Scand [Suppl] 1964;73.

Markolf KL. Deformation of the thoracolumbar intervertebral joints in response to external loads.J Bone Joint Surg [Am] 1972;54-A:51 1-33.

Nachemson AL. The influence of spinal movements on the lumbar intradiscal pressure and on the tensile stresses in the annulus fibrosus. Acta Orthop Scand 1963;33:183-207.

Nachemson AL. The load on lumbar disks in different positions of the body. Clin Orthop 1966;45:107-22.

Nade S, Bell E, Wyke BD. The innervation of the lumbar spinal joint and its significance. J Bone Joint Surg [Br] 1980;62-B:255. 